\title{
Looking at Soviet Geology
}

Twice in the past, in 1897 and in 1937, the U.S.S.R. has played host to the International Geological Congress. So as to set the scene for the 27 th Congress, to be held this August once again in the Soviet Union, we devote the bulk of this special issue of Episodes to the geology and mineral resources of that country.

As R. Trümpy, the Past President of IUGS, has pointed out, geologists were among the first scientists to convene internationally in order to exchange ideas, to become acquainted with the natural framework of other areas and to establish scientific standards. From these early Congresses came a variety of commissions and other bodies, and as these organizations and their tasks became more numerous and complex, the need for liaison and coordination increased. IUGS was established in 1961 to meet these needs and, though originally a "child" of the Congress, the Union has now become its main sponsor. The key role of IUGS is to facilitate communications among geologists in a non-governmental framework. In sponsoring the Congress, IUGS does so with the view of maintaining scientific communications despite existing economic, social and political conditions.

Naturally, the gigantic task of organizing a Congress must be undertaken by the host country and its national institutions in the present case, the Ministry of Geology and the Academy of Sciences of the U.S.S.R. The Union provides advice where needed, especially on the scientific programs, and many of the IUGS commissions, subcommissions, committees, and affiliated societies use this opportunity to hold their own business meetings and scientific sessions. For example, as reported elsewhere in this issue, the Commission on Stratigraphy, which is the largest member of the IUGS family, will hold its quadrennial meeting in Moscow, at which time many proposals for stratigraphic standards will be presented.

But the Congress is also a useful occasion for the host nation, as its scientists work feverishly to produce maps, reviews and field guides that might otherwise have waited for years. According to the President of the Congress, Ye.A. Kozlovsky, this is certainly true for the Soviet Union, which is offering many field excursions throughout its vast, varied and complex territory, as well as new and comprehensive publications describing its geology and mineral resources.

The reviews in this issue by leading Soviet geologists highlight some of the areas and topics of special concern to the U.S.S.R. Minister Kozlovsky and A.L. Yanshin give an overview of the main themes of interest to Soviet geologists, and papers by A.I. Zhamoida, B.S. Sokolov and M.A. Fedonkin, and $A$.Yu. Rozanov emphasize the importance of stratigraphy to their country and of Soviet strata to the world. Soviet approaches to metallogenesis are outlined by V.I. Smirnov and D.V. Rundquist. Two papers on regional geology by A.M. Dymkin and V.N. Puchkov (the Urals) and N.A. Logatchev (the Baikal rift), and the summary of lithospheric layering by S.V. Ruzhentsev and V.G. Trifonov provide a general look at the way in which Soviet geologists interpret the structure of their landmass. To underscore this aspect we include a recently released map of the U.S.S.R. showing the plate boundaries now recognized by some workers.

Many outsiders unfamiliar with Soviet geoscience may regard it as rather monolithic - an impression heightened by the language barrier, the characteristic style of scientific com- munications, and the very distinct structure of science. The short summary by D.P. Lobanov and E.D. Yershov of geological education in the U.S.S.R exemplifies the latter for many in the foreign geoscience community. Yet differences in interpretation among some of the authors in even this tiny sampling demonstrate the vitality of Soviet geoscience. Differences between many of their models and approaches and those popular elsewhere underscore the important contributions that geologists in the U.S.S.R. are making to the advancement of our field.

Naturally there are many important aspects to Soviet geology not included here: its massive oil and gas deposits, its surficial deposits, and the major contributions of Russian scientists to such disciplines as mineralogy, geochemistry and engineering geology. Some of these will be reviewed in forthcoming issues of Episodes, but the most comprehensive overview of Soviet geology will be available to those who attend the Congress in August, participate in the field excursions and exchange views with Soviet geologists.

This issue of Episodes would not have been possible without the cooperation and assistance of the U.S.S.R. National Committee of Geologists, headed by IUGS Vice-President V.V. Menner and R.I. Volkov, its Executive Secretary. IUGS is grateful to them, and to the staff of the Geological Survey of Canada who provided much of the necessary technical back-up, especially for the many illustrations that were redrawn in Ottawa. As regards terminology, we have retained terms defined in the AGI Glossary of Geology and attempted to explain those not included. We have also taken the opportunity to cite some of the recent geological literature on the U.S.S.R. that is available in English.

Finally, we note that this issue is being distributed by the Congress organizers to all registrants of the Congress. It is also going out, like all the 1984 issues, to over 200 geoscience institutions in developing countries, under the terms of a contract with Unesco for dissemination of geological information. This is the second year for this arrangement, which is a very practical example of international scientific cooperation. "Cooperation" because, despite the harsh economic conditions in many such regions, as IUGS becomes better known in Africa, Asia and Latin America, there is a tangible increase in participation by scientists there in the programs and activities of the Union and Unesco (e.g. IGCP, ICL, Geology for Development) and a corresponding advance in our knowledge of science and in our ability to manage natural ear th resources.

\section{FORTHCOMING ARTICLES}

The PreCordillera of the Argentinian Andes

Precambrian Fossil Soils

Volcanic Hazards in Indonesia

The Caspian Basin

Sedimentary Precursors and Metamorphism 